\title{
VARIATION OF PRECIPITATION CONCENTRATION FROM 1960 TO 2014 IN THE MIDDLE AND LOWER REACHES OF YANGTZE RIVER BASIN, CHINA
}

\author{
L. ZHAO, J.M. WANG, Z. ZHAO, J. FANG*
}

School of Resource and Environmental Sciences, Wuhan University, China.

\begin{abstract}
Based on the daily rainfall data of 127 stations from 1960 to 2014, this study investigated the spatial-temporal variation of PCD (precipitationconcentration degree) and PCP (precipitation-concentration period), and their possible relations with ENSO (El Niño-Southern Oscillation) in the middle and lower reaches of Yangtze River of China. Main results have indicated that, firstly, the mean PCD was generally below 0.5 across the whole study area, with the lower value located in the northeast and south. Besides, there was a positive trend of concentrated precipitation in the west part while negative in the east. Secondly, the mean PCP ranged from May to July and delayed from south to north, along with a trend of advancing rainy season in the central part. In addition, PCD had a positive relation with ONI (Oceanic Niño Index), while PCP negative. El Niño led the rainy season earlier and the precipitation more concentrated. This study could not only shed a light on the understanding of the variation of precipitation pattern, but also provide theoretical support for regional disaster risk governance and water resources management in the middle and lower Yangtze River Basin.
\end{abstract}

Variación de la concentración de precipitación desde 1960 a 2014 en la cuenca media e inferior del Río Yangtze, China

RESUMEN. Basándose en la precipitación diaria de 127 estaciones desde 1960 hasta 2014, este estudio se ha centrado en la variación espacio-temporal del PCD (Grado de concentración de la precipitación) y el PCP (Periodo de concentración de la precipitación), y sus posibles relaciones con ENSO (Oscilación Meridional de El Niño) en los tramos medio e inferior del Río Yangtze de China. Los principales resultados indican en primer lugar que el PCD medio estuvo generalmente por debajo de 0,5 en todo el área de estudio, localizándose el valor más bajo en el nordeste y en el sur. Además, hubo una tendencia positiva de la precipitación concentrada en la parte occidental, mientras que fue negativa en la oriental. En segundo lugar, el PCP medio osciló de mayo a julio y se retrasó de sur a norte, junto con una tendencia a avanzar la estación lluviosa en la parte central. Por otro lado, el PCD tuvo una relación positiva con ONI (Índice 
Oceánico de EL Niño), siendo negativa con el PCP. El Niño hizo que la estación lluviosa ocurriera antes y que el periodo de precipitación fuera más concentrado. Este estudio pudo no sólo arrojar más luz a la comprensión de la variación de los patrones de precipitación, sino también proporcionar un apoyo teórico a la gobernanza de los riesgos de desastres regionales y la gestión de los recursos hídricos en la cuenca media e inferior del Río Yangtze.

Key words: precipitation concentration, spatio-temporal variation, ENSO, Yangtze River Basin.

Palabras clave: concentración de la precipitación, variación espacio-temporal, ENSO, Cuenca del río Yangtze.

Received 9 January 2016

Accepted 22 February 2016

*Corresponding author: J. Fang, School of Resource and Environmental Sciences, Wuhan University, Wuhan 430079, China. E-mail: fj20061028@126.com

\section{Introduction}

Under global warming, the impacts of climate change upon the extreme meteorological events have drawn more and more concerns among the international scientific issues and the public (IPCC, 2007, 2013). The climate change impacts have various spatial-temporal scales and different characteristics. As one of the vital factors in global water cycle, mean precipitation and extremes have been affected globally by climate change in recent decades (IPCC, 2007, 2013). Due to the variation of its driving factors, precipitation patterns vary among different regions and seasons (Huang et al., 2013; Marvel et al., 2013). The concentration of precipitation in space and time is very sensitive to climate change and would induce the occurrence of more frequent extreme climate events. The uneven distribution of rainfall can lead to more flood or drought, soil erosion and other related disasters, which will affect agriculture ecosystem, grass and forest ecosystem, the safety of property and citizens, and so on (Arnaud et al., 2002; Huang et al., 2013; Wang et al., 2014). Therefore, studying the temporal and spatial distribution of the precipitation concentration is of great importance to help us facing the risk of climate change and understanding the regularity and formation mechanism of climate change (Stott et al., 2010; Gu and Andler, 2015).

In recent years, a few tools have been developed to measure the distribution and concentration of rainfall, such as MFI (Modified Fournier Index; Arnoldus, 1977), PCI (Precipitation Concentration Index; Oliver, 1980) and PCD (Precipitation Concentration Degree; Zhang and Qian, 2003). Based on long-term rainfall intensity data, MFI and PCI could be used to estimate the rainfall erosivity (Renard and Freimund, 1994; Munka et al., 2007; Mello et al., 2013). After comparing PCI with MFI, Apaydin et al. (2006) stated that PCI was more suitable to reflect the concentration of precipitation. Another method of calculating the precipitation concentration, PCD (precipitation concentration degree) 
and PCP (precipitation-concentration period), were developed in 2003 (Zhang and Qian, 2003). By using composite vector, they are more suitable to show the concentration and the barycenter date of rainfall and their comprehensive effects. Thus, PCD and PCP became widely used in China (Zhang and Qian, 2004; Bai and Liu, 2010; Wang et al., 2013; Kong et al., 2015) and may also be suitable for other places (Silva and Lucio, 2015). The characteristics of PCD and PCP depend on the diverse distribution patterns of precipitation, and differ significantly across China. Generally, the concentration degrees in the arid or semi-arid regions of China were larger than that in humid regions, which have long rainy seasons (Zhang and Qian, 2003; Kong et al., 2015).

As the most typical river in the humid region of China, Yangtze River is the longest and largest river in China (also the third longest river in the world), flowing across 19 provinces (Fig. 1). The uneven temporal distribution of precipitation in the Yangtze River basin makes it very prone to droughts and floods (Zhang et al., 2008; Zhai et al., 2010). Furthermore, the middle and lower reaches of Yangtze River, of subtropical monsoon climate, are more sensitively affected by the summer Asian-Pacific monsoon (Wang and Ho, 2002; Liu et al., 2011). The frequent extreme precipitation and its variation in the middle and lower reaches of Yangtze River will have negative effects on grain-producing, water supply and social security.

Therefore, the purpose of this study is to analyze the spatial and temporal distribution and variation of precipitation concentration in the middle and lower reaches of Yangtze River from 1960 to 2014. By utilizing PCD/PCP as the indicator of the concentration of precipitation, this study aims to clarify the temporal and spatial characteristics of $\mathrm{PCD} /$ PCP and further explore their possible relationships with ENSO events. The results will be of great importance for further understanding of climate change impact and regional disaster risk reduction.

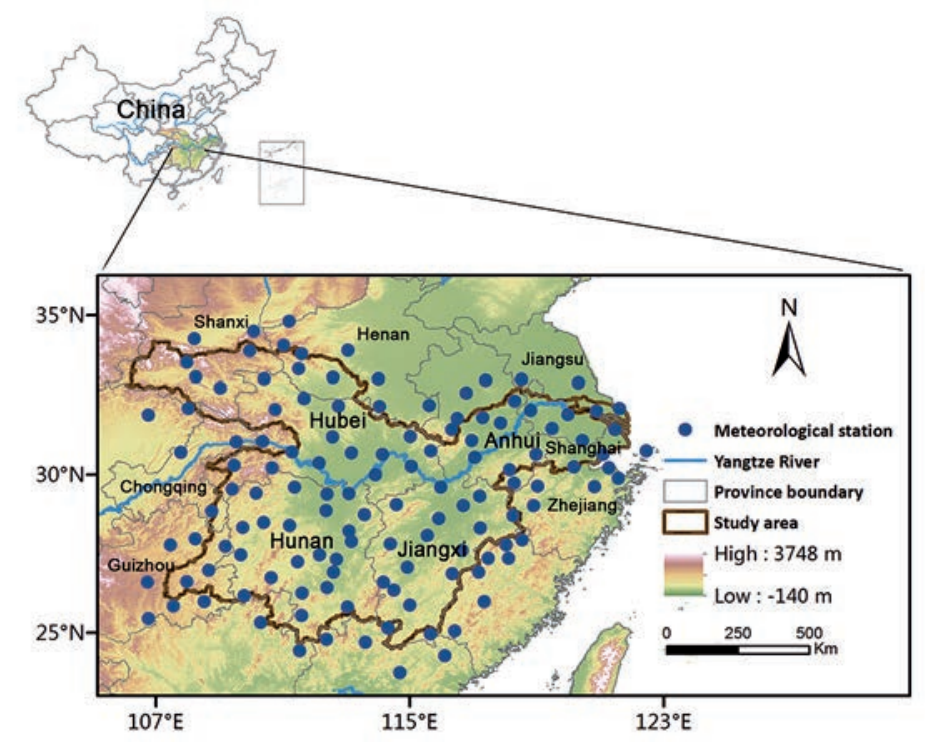

Figure 1. Location of the study area and weather stations. 


\section{Data and methods}

\subsection{Study area and datasets}

The location of the middle and lower reaches of Yangtze River basin and the weather stations are depicted in Fig. 1. There are 78 stations located in the study area and 49 stations in the around buffer zone $100 \mathrm{~km}$ out of the study area boundary. The daily precipitation data of 127 stations used in this study are provided by China Meteorological Data Sharing Service System (http://cdc.nmic.cn), covering the period between 1960 and 2014. Data quality has been checked before they were used for calculation of PCD and PCP. The seasonality of rainfall and the changing trend of annual rainfall in this area are shown in Fig.2. Besides, according to Zhang et al. (2004), in early 1990s, there were obvious jump points for the trends of PCD and PCP based on the M-K test. Thus, we also separate the whole period into two sub-periods 1960 to 1989 and 1990 to 2014, for the purpose of the following comparison and transition analysis.
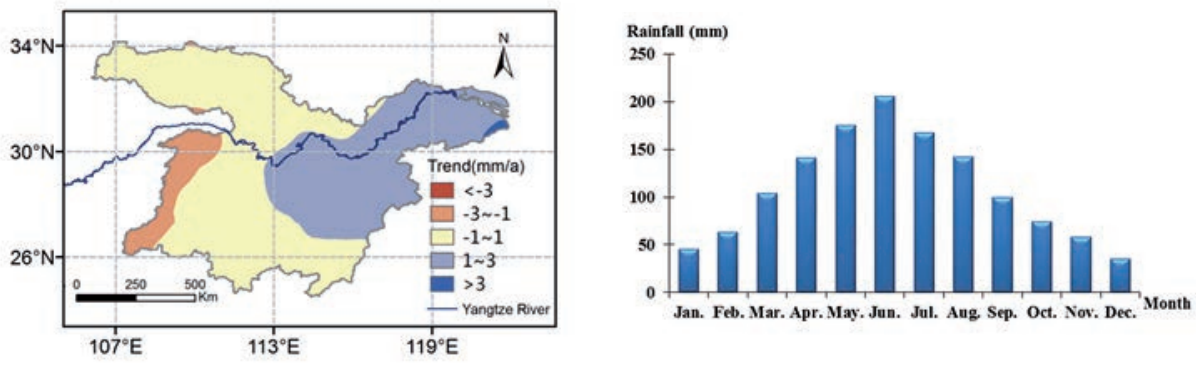

Figure 2. Monthly mean precipitation (right) and changes in annual precipitation (left) in the middle and lower reaches of Yangtze River basin.

\subsection{Computation of $P C D / P C P$}

The PCD and PCP were proposed by Zhang et al. (2003) to measure the distribution of rainfall and the peak rainfall date. They were calculated as follows:

$$
\begin{gathered}
\theta_{j}=\left(360^{\circ} * \frac{j}{n}\right) \\
R_{x i}=\sum_{j=1}^{N} r_{i j} * \sin \theta_{j} \\
R_{y i}=\sum_{j=1}^{N} r_{i j} * \cos \theta_{j} \\
P C D_{i}=\frac{\sqrt{R_{x i}{ }^{2}+R_{y i}^{2}}}{R_{i}}
\end{gathered}
$$


where i refers to the year $(1960,1961, \ldots, 2014), \mathrm{j}$ is the day of that year $(1,2,3 \ldots \ldots .364,365)$, $\mathrm{R}_{\mathrm{i}}$ is the amount of rainfall of a year, $\mathrm{r}_{\mathrm{ij}}$ is the precipitation of the $\mathrm{j}_{\mathrm{th}}$ day in the $\mathrm{i}_{\text {th }}$ year.

$$
\begin{aligned}
& \alpha_{i}=\arctan \left(R_{x i} / R_{y i}\right) \\
& D_{i}= \begin{cases}\alpha_{i} & \left(R_{y i} \geq 0, R_{x i} \geq 0\right) \\
\alpha_{i}+360^{\circ} & \left(R_{y i}>0, R_{x i}<0\right) \\
\alpha_{i}+180^{\circ} & \left(R_{y i}<0\right)\end{cases} \\
& P C P_{i}=D_{i} * \frac{n}{360^{\circ}}
\end{aligned}
$$

where $D_{i}$ is the azimuth of PCP. During a non-leap year, $n=365$, while in a leap year, $\mathrm{n}=366$. Actually, the scale (including $\mathrm{i}$ and $\mathrm{j}$ ) can be adjusted to meet the specific need. In this study, we use daily precipitation and calculate the PCD/PCP of each year.

In formula (4), PCD is the ratio of resultant vector to total amount of precipitation, which is able to reflect the concentration degree of rainfall during a year. If PCD equals 1 , the resultant vector equals to the total, indicating the max degree of concentration, whereas, if every component equals, the min PCD is 0. It is shown in formula (5), (6) and (7) that PCP nearly demonstrates the barycenter date of precipitation during a year. More details of this method can be found in Zhang et al. (2003).

\subsection{ENSO index and typical events}

\subsubsection{The Oceanic Niño Index (ONI)}

The Oceanic Niño Index (ONI) is the 3-month moving average of ERSST.v4 SST anomalies in the Niño 3.4 region $\left(5^{\circ} \mathrm{N}-5^{\circ} \mathrm{S}, 120^{\circ}-170^{\circ} \mathrm{W}\right)$. A warm period, when $\mathrm{ONI}>0.5$ for at least 5 consecutive months, refers to an El Niño event. Similarly, cold periods, when the ONI is below -0.5 for more than 5 months continuously, generally represent La Niña events. The ONI data are provided by the climate prediction center of National Weather Service (http://www.cpc.noaa.gov). As most of the El Niño or La Niña events contain a period from June to February of next year, we averaged the monthly ONI from June to February (including summer, autumn and winter) and denoted as ONIsAW to represent the phenomenon of ENSO in that year.

\subsubsection{Selection of typical ENSO events}

According to the ONI time series from 1960 to 2014, the beginning and ending time of each abnormal period along with their average ONI are shown in Table 1. The termination year of ENSO events was used to denote the specific ENSO event. In this study, we choose 2 typical El Niño events $(1973,1998)$, and 2 of La Niña events (1974, 2011), of which the absolute value of average ONI rank first in the two sub-periods respectively. 
Table 1. Average ONI and the beginning and ending time of ENSO events from 1960 to 2014 (Selected typical ENSO events are in Bold)

\begin{tabular}{|c|c|c|c|c|c|c|}
\hline Sub-periods & El Niño & $\begin{array}{c}\text { Termination } \\
\text { year }\end{array}$ & $\begin{array}{c}\text { Average } \\
\text { ONI }\end{array}$ & La Niña & $\begin{array}{c}\text { Termination } \\
\text { year }\end{array}$ & $\begin{array}{c}\text { Average } \\
\text { ONI }\end{array}$ \\
\hline \multirow[b]{4}{*}{1960} & 1963.7-1964.2 & 1964 & 0.99 & 1964.5-1965.1 & 1965 & -0.70 \\
\hline & \begin{tabular}{|l|}
$1965.6-1966.4$ \\
\end{tabular} & 1966 & 1.22 & \begin{tabular}{|l|}
$1967.12-1968.4$ \\
\end{tabular} & 1968 & -0.64 \\
\hline & \begin{tabular}{|l|}
$1968.11-1969.6$ \\
\end{tabular} & 1969 & 0.75 & 1970.7-1972.1 & 1972 & -0.88 \\
\hline & \begin{tabular}{|l|}
$1969.8-1970.1$ \\
\end{tabular} & 1970 & 0.70 & 1973.6-1974.7 & 1974 & -1.26 \\
\hline \multirow{2}{*}{ to } & \begin{tabular}{|l|}
$1972.5-1973.3$ \\
\end{tabular} & 1973 & 1.32 & 1974.10-1976.3 & 1976 & -0.93 \\
\hline & 1976.9-1977.2 & 1977 & 0.68 & 1984.10-1985.6 & 1985 & -0.77 \\
\hline \multirow[t]{4}{*}{1989} & \begin{tabular}{|l|}
$1977.9-1978.1$ \\
\end{tabular} & 1978 & 0.68 & 1988.5-1989.5 & 1989 & -1.23 \\
\hline & \begin{tabular}{|l}
$1979.10-1980.2$ \\
\end{tabular} & 1980 & 0.54 & & & \\
\hline & \begin{tabular}{|l|}
$1982.4-1983.6$ \\
\end{tabular} & 1983 & 1.30 & & & \\
\hline & 1986.9-1988.2 & 1988 & 1.09 & & & \\
\hline \multirow[b]{2}{*}{1990} & 1991.6-1992.7 & 1992 & 1.01 & 1995.8-1996.3 & 1996 & -0.78 \\
\hline & \begin{tabular}{|l|}
$1997.5-1998.5$ \\
\end{tabular} & 1998 & 1.56 & 1998.7-2001.3 & 2001 & -0.99 \\
\hline \multirow{2}{*}{ to } & 2002.6-2003.2 & 2003 & 0.94 & $2007.8-2008.6$ & 2008 & -0.99 \\
\hline & 2004.7-2005.4 & 2005 & 0.62 & 2010.7-2011.4 & 2011 & -1.11 \\
\hline \multirow[t]{2}{*}{2014} & 2006.9-2007.1 & 2007 & 0.78 & 2011.8-2012.3 & 2012 & -0.70 \\
\hline & 2009.7-2010.4 & 2010 & 0.90 & & & \\
\hline
\end{tabular}

\section{Results}

\subsection{PCD and PCP from 1960 to 2014}

Fig. 3 shows the temporal variation of averaged PCD/PCP, spatial distribution of annual mean PCD and PCP and their linear trends in the middle and lower reaches of Yangtze River from 1960 to 2014. From Fig. 3a, it can be inferred that generally the mean PCD of whole study area is 0.39 and lower than that in arid and semi-arid regions of China (Zhang et al., 2004). PCD of over $93 \%$ areas are under 0.5 , which may be attributed to the long rainy season in this study area. Secondly, the mean PCD varies slightly in this area. Areas with PCD between from 0.3 to 0.5 occupy nearly $90 \%$ of the whole region. Besides, the PCD increases gradually from south to north in general. It is fairly high (over 0.5 ) in northwest, while low (under 0.3 ) in the south of the central (low latitude) and the northeast (near seaside) part.

For the PCP (Fig. 3b), the mean of the whole region is 24th week, when the East Asian rainy season starts in most regions. PCP of over $97 \%$ areas are between the 20th to the 29th week of year (the 133th to 203th day of year), leading to regular floods in this study area. Meanwhile, the spatial variation of PCP is much more obvious than that of PCD. From southeast to northwest, the PCP increases significantly, indicating that precipitation in this area is dominated by East Asia monsoon, in which the rain belt moves from southeast to northwest. 


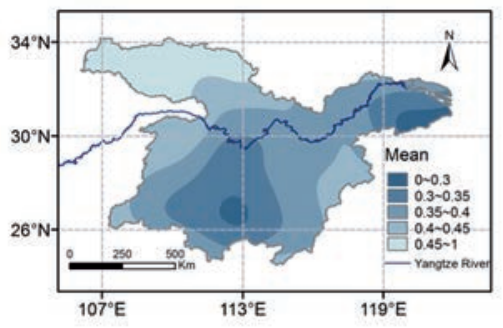

a

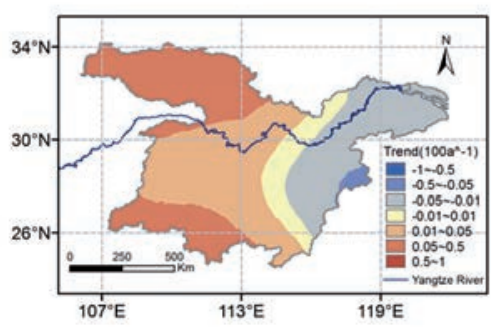

c

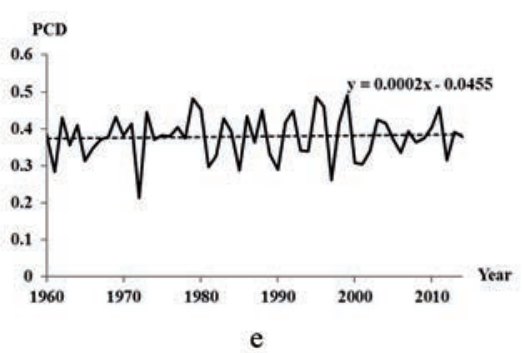

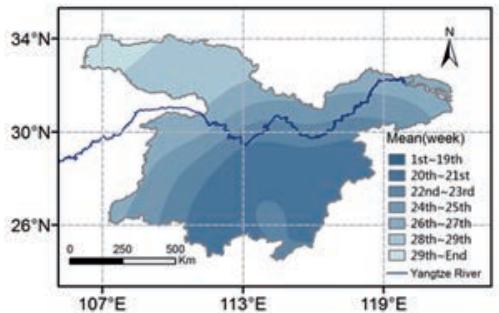

b

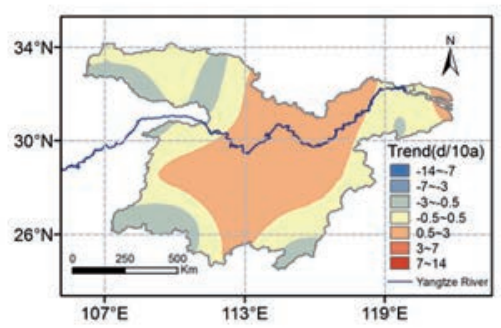

d

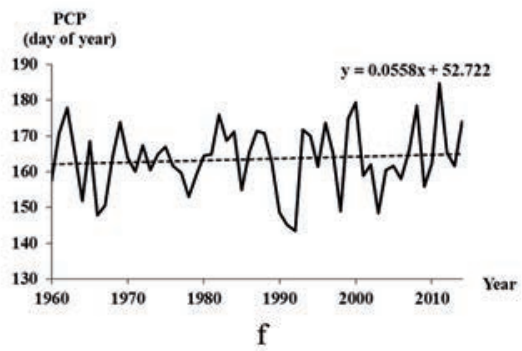

Figure 3. Mean PCD and PCP and their linear trends from 1960 to 2014 ( $a$ is mean PCD, $b$ is mean PCP, $c$ is the linear trend coefficient of PCD, $d$ is the linear trend coefficient of PCP, $e$ is the time series of averaged $P C D, f$ is the time series of averaged $P C P$ ).

The linear trend coefficients of PCD were depicted in Fig. 3c. Generally, the trends of PCD differ significantly from east to west. Specifically, negative trends occur in the east part, whereas positive trends locate mainly in the middle and west. Higher positive trend coefficients are found in northwest and southwest part. In other words, the precipitation became more and more concentrated in the west part from 1960 to 2014, while more and more even in the east part. This indicates that the risk of extreme climate events such as floods and droughts grows in the northwest part of this study area.

Fig. 3d shows the linear trend of PCP from 1960 to 2014. It illustrates that most area have a positive liner trends of PCP (1-3d/10a), especially in the middle part. The neutral or negative linear trend coefficients are distributed in some other parts of the study area. This indicates that the barycenter of annual precipitation has a remarkable trend of delaying rather than advancing in the middle part, which means that monsoon dominating major precipitation delay gradually. 
Taking this region as a whole, there is no significant trend of average PCD during the whole period (Fig. 3e). For average PCP (Fig. 3f), there is a slight increasing trend from 1960 to 2014, which indicates lag of precipitation concentration period. The increasing trend of PCP after 1990 is significant.

\subsection{Transition of PCD/PCP during two sub-periods}

\subsubsection{Transition of PCD during two sub-periods}

The spatial variations of mean PCD during two sub-periods (1960-1989, 1990-2014) are illustrated in Fig. 4a and Fig. 4b. Generally, the spatial distribution of mean PCD during two sub-periods are very similar to that from 1960 to 2014 (Fig. 4a). Higher values occur in the northwest part, while lower values in the south and east part. Most of the mean PCD during these two sub-periods also range from 0.3 to 0.5 . However, minor changes can still be found. From former sub-period (1960-1989) to latter sub-period (1990-2014), the mean PCD of the south part turns to be higher. Meanwhile, the PCD of the southeast part turns to be lower.

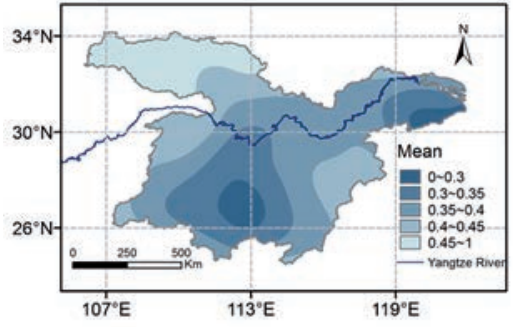

a

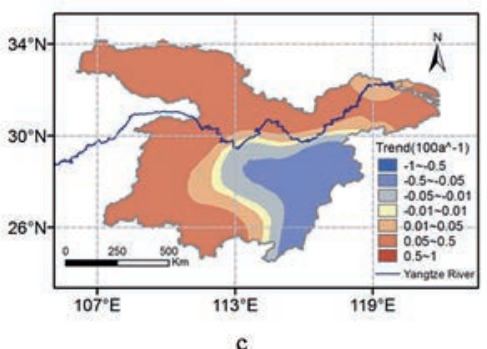

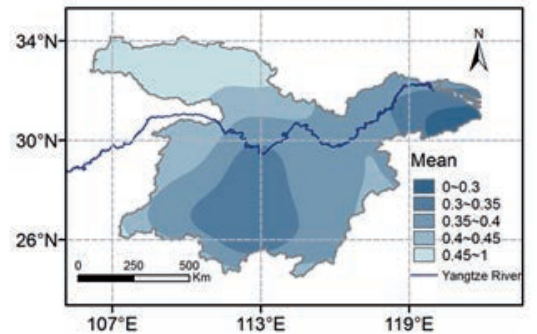

b

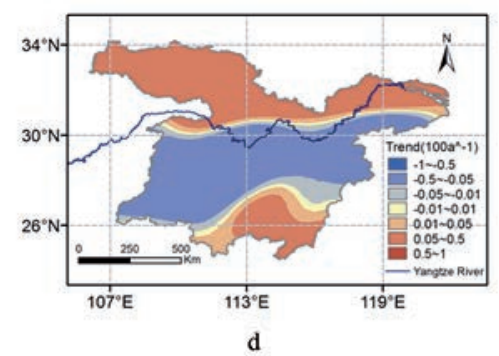

Figure 4. Annual mean PCD and the linear trends during two sub-periods ( $a$ is annual mean PCD in 1960-1989, b is annual mean PCD in 1990-2014, $c$ is the linear trend coefficient of PCD in 1960-1989, $d$ is the linear trend coefficient of PCD in 1990-2014).

Fig. 4c and Fig. 4d show the significant transition of PCD trend from 19601989 to 1990-2014. Overall, the spatial pattern of PCD trend coefficients from 1960 to 1989 is generally similar to that from 1960 to 2014 (Fig. 3c), demonstrating that negative trend occur in the east part and positive in the west part. However, the spatial distribution of PCD trend from 1990 to 2014 differs a lot, with positive trends mainly in the north and south part and negative trends in the middle part (Fig. 4d). In addition, there is 
a significant transition of PCD trend from positive to negative in the southwest part, and negative to positive in the southeast part. Furthermore, the comparatively higher PCD value (Fig. 4a-b) and its positive trend (Fig. 4c-d) in the northwest part reveal that precipitation in this specific area is becoming more and more concentrated, which will cause a high risk of suffering from flood or drought.

\subsubsection{Transition of PCP during two sub-periods}

As is shown in Fig. 5a-b, the spatial distributions of mean PCP during two subperiods are very similar in general. As what is indicated in Fig. 3b, the mean PCP increases gradually from southeast to northwest part in both periods, except for an area in the south part with higher PCP than the surrounded regions.
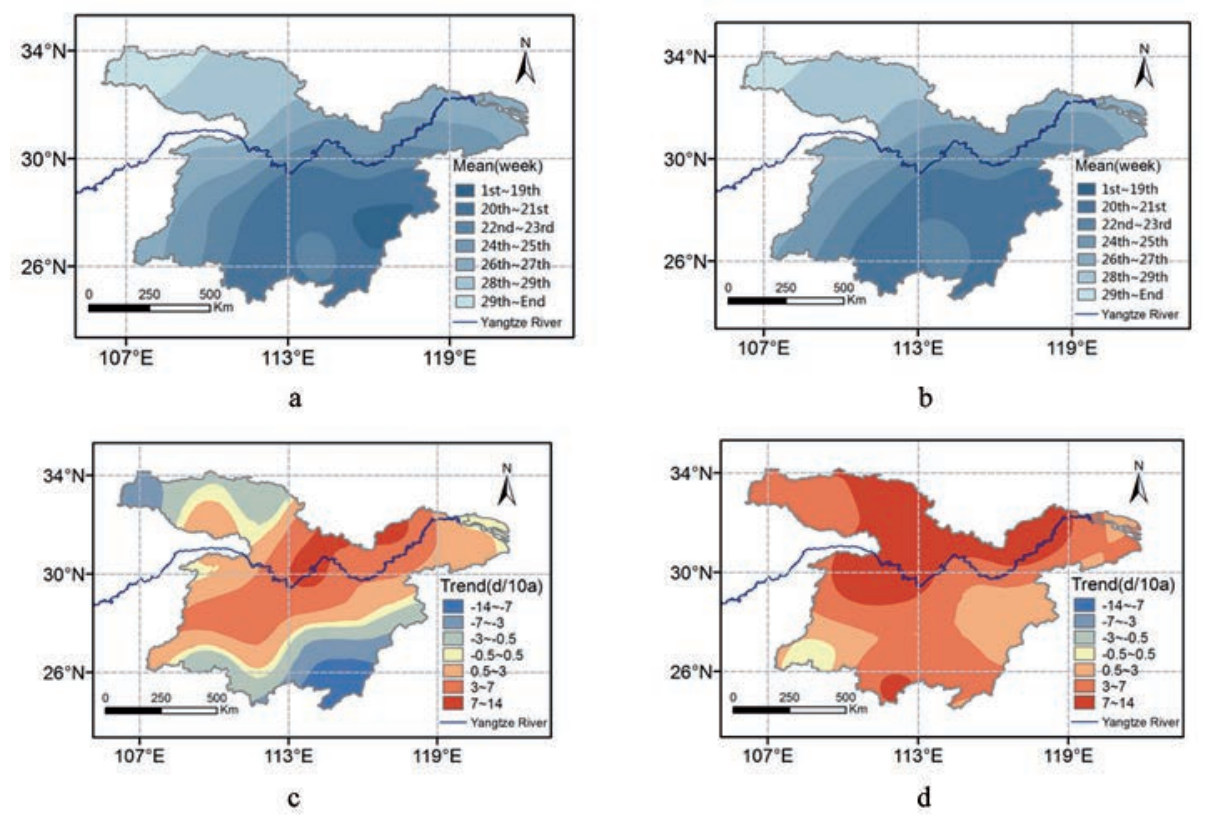

Figure 5. Annual mean PCP and the linear trends during two sub-periods ( $a$ is annual mean PCP in 1960-1989, b is annual mean PCP in 1990-2014, $c$ is the linear trend coefficient of PCP in 1960-1989, $d$ is the linear trend coefficient of PCP in 1990-2014).

Spatial distributions of liner trend coefficients of PCP during 1960-1989 and 19902014 are significantly different from each other (Fig. 5c and Fig. 5d). In the former subperiod, the positive PCP trends occur in about $60 \%$ of the area except for the southeast and northwest part. While in the latter sub-period, the positive PCP trend occurs in almost the whole study area, with the higher value in the north part. This manifests that the delay of monsoon induced precipitation become more and more notable in most region of the study area. Especially in the north part, the mean PCP and PCD are both high and their trends are positive too (Fig. 4 and Fig. 5), which make it very susceptible to more extreme rainfall in rainy seasons and frequent and severe droughts in non-rainy season. 


\subsection{Relationships between $O N I$ and PCD/PCP}

\subsubsection{Correlation between ONI and PCD/PCP}

To further reveal the possible driving factor of $\mathrm{PCD} / \mathrm{PCP}$ variations, we investigated the relationships between $\mathrm{PCD} / \mathrm{PCP}$ and ENSO, which may impact the major timing and intensity of precipitation in East Asia. The Spearman correlation coefficients between $\mathrm{ONI}$ and PCD/PCP in different periods are shown in Fig. 6. In general, it indicates almost all positive correlations between ONI and PCD, while negative between ONI and PCP except for the period from 1960 to 1989.

During the entire period (1960-2014), the majority of coefficients in Fig. 6a are less than 0.3 , indicating an overall weak positive correlation between ONI and PCD, while there are higher significant positive coefficients in the middle part $(\mathrm{R}>0.3$ and $\mathrm{P}<0.05)$. For $\mathrm{PCP}$, though there are significant negative coefficients $(\mathrm{R}<-0.3$ and $\mathrm{P}<0.05)$ in the northeast and the southeast parts, most of the correlation coefficients in the middle and west are between -0.3 to 0 , indicating an overall weak negative correlation between ONI and PCP (Fig. 6b).
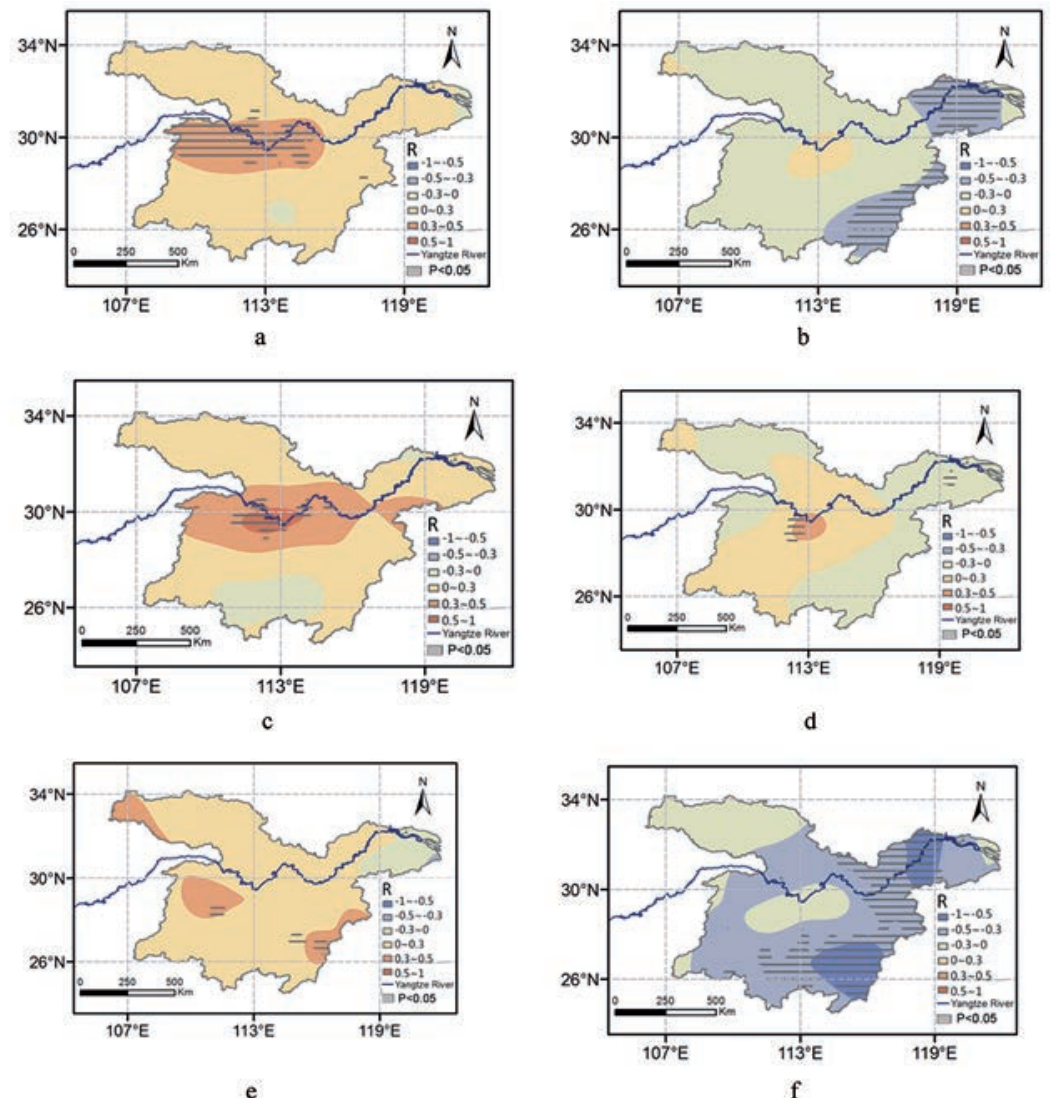

Figure 6. Correlation coefficients between $P C D / P C P$ and $O N I$ (a,c,e are for PCD-ONI correlation in 1960-2014, 1960-1989, 1990-2014 respectively, b, $d$, f are for PCP-ONI correlation in 1960-2014, 1960-1989, 1990-2014 respectively). 
During the two sub-periods (1960-1989 and 1990-2014), there are different transitions regarding to correlation of ONI-PCD and ONI-PCP. For PCD, there is no significant transition between two sub-periods (Fig. 6c and Fig. 6e). The correlations between ONI and PCD are positive in general and the spatial patterns are similar to that of the entire period which indicates an area with higher coefficient in the central part. By comparison, the positive correlation between ONI and PCD from 1960 to 1989 is much stronger than that from 1990 to 2014. As far as the correlation between ONI and PCP is concerned, there is significant transition from general positive to negative in the central part during two sub-periods (Fig. 6d and Fig. 6f). The overall strong negative correlation from 1990 to 2014 contributes a lot to the general weak negative correlation in the entire period. These results above manifest that El Niño/La Niña will probably cause the precipitation in this study area more concentrated/even in a year cycle. Besides, El Niño/La Niña may lead to the rainy season earlier/later, especially during recent three decades.

\subsubsection{PCD and PCP in typical ENSO events}

Comparative analyses of PCD/PCP during typical El Niño/La Niña events are presented in Fig. 7 and Fig. 8. Regarding to PCD during El Niño events (Fig. 7a and Fig. $7 \mathrm{~b}$ ), the departure percentage of PCD are generally positive. Table 2 indicates that $91.5 \%$ of area are under positive departure of PCD in El Niño 1973 especially in the central part where the departure percentage is over $30 \%$, while only a small part of northwest is under weak negative departure of PCD. In El Niño 1998, 80.5\% of area is also under positive departure of PCD, while a small part of east shows negative. This result is in accordance with that indicated in Fig. 6, which manifests positive correlation between ONI and PCD.

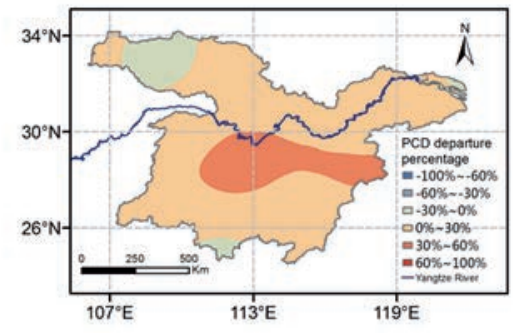

a

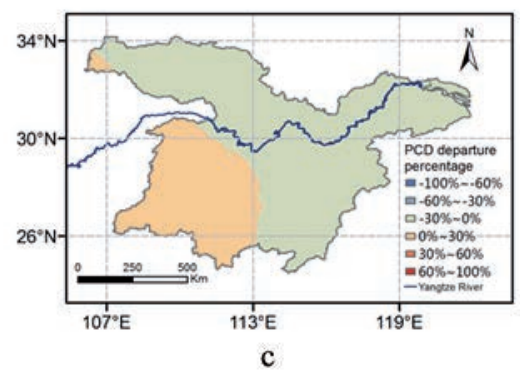

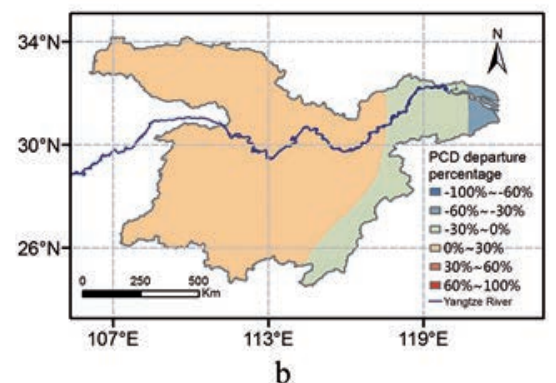

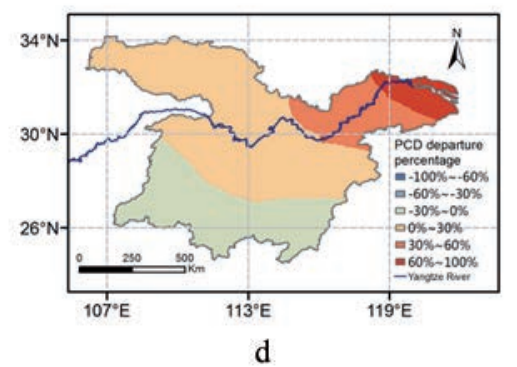

Figure 7. PCD departure percentages in 1973(a), 1998(b), 1974(c), 2011(d) (a and b are El Niño events, while c and d are La Niña events). 

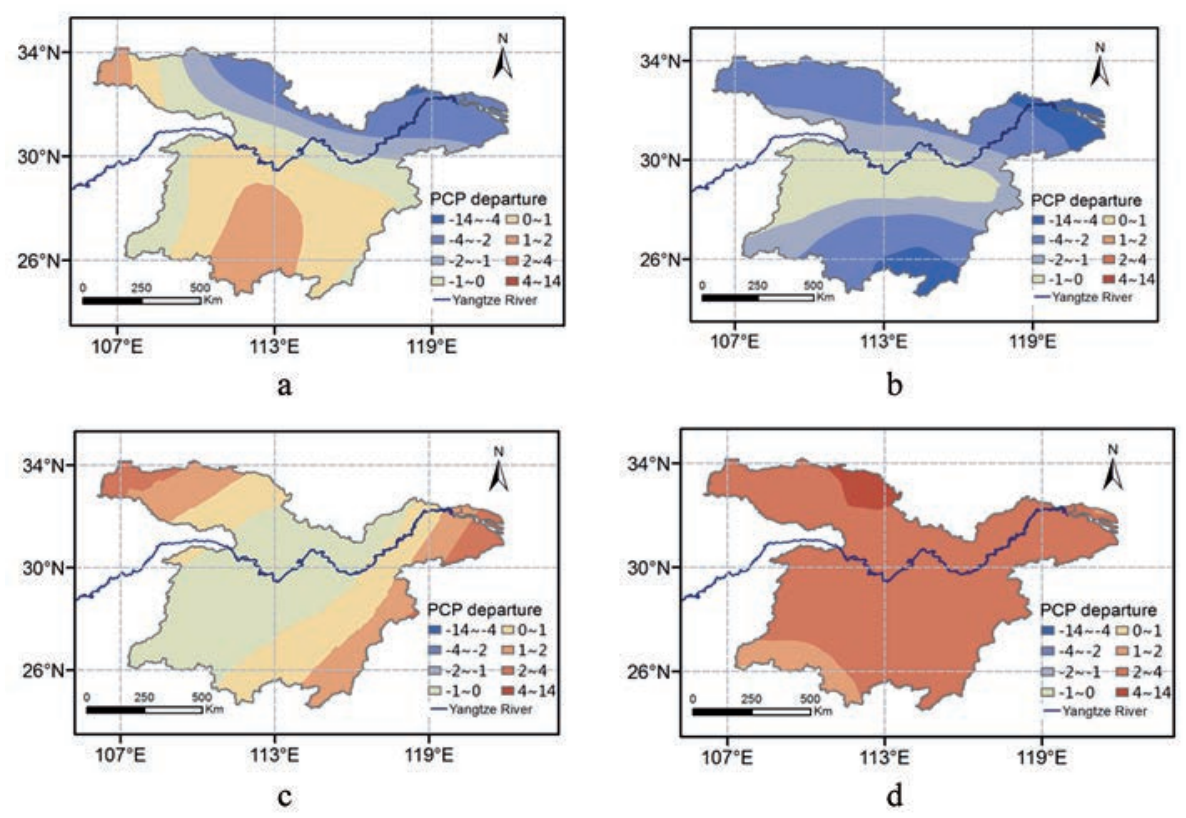

Figure 8. PCP departures in 1973(a), 1998(b), 1974(c), 2011(d) ( $a$ and $b$ are El Niño events, while $c$ and $d$ are La Niña events).

In contrast, during La Niña events, the performances of PCD during these two events (1974 and 2011) are not consistent. In La Niña 1974 (Fig. 7c), although the departure percentage is not so high, $70.8 \%$ of area are under negative departure of PCD, which is in well agreement with the general strong positive correlation between ONI and PCD during 1960-1989 presented in Fig. 6c. While in La Niña 2011 (Fig. 7d), 72.1\% of area are under positive. From this point of view, generally it seems to be not in agreement with the correlation result showed in Fig. 6e. However, specifically the northeast and northwest parts which are under positive departure in La Niña 2011 (Fig. 7d) also agree with the weak negative correlation presented in Fig. 6e.

Table 2. Percentages of area under positive/negative PCD departures during four typical ENSO events.

\begin{tabular}{|l|c|c|c|c|}
\hline \multirow{2}{*}{ Percentages of area } & \multicolumn{2}{|c|}{ El Niño events } & \multicolumn{2}{c|}{ La Niña events } \\
\cline { 2 - 5 } & 1973 & 1998 & 1974 & 2011 \\
\hline Positive departure & $91.5 \%$ & $80.5 \%$ & $29.2 \%$ & $72.1 \%$ \\
\hline Negative departure & $8.5 \%$ & $19.5 \%$ & $70.8 \%$ & $27.9 \%$ \\
\hline
\end{tabular}

Regarding to PCP during typical El Niño/La Niña events, the PCP departures are negative/positive in general. However, the percentage of area that are under negative or positive departure do not dominate in El Niño 1973 (Fig. 8a, Table 3) and La Niña 
1974 (Fig. 8c, Table 3), which partly proves the general weak correlation between ONI and PCP from 1960 to 1989 (Fig. 6d). By comparison, the whole area is under negative departure in El Niño 1998 (Fig. 8b, Table 3), mostly over one week ahead of time. In La Niña 2011 (Fig. 8d, Table 3), the whole are is under positive departure, mostly delaying more than 2 weeks. This totally negative/positive departure of PCP in El Niño/ La Niña further confirms the strong negative correlation between ONI and PCP from 1990 to 2014 that is indicated in Fig. 6 f.

Table 3. Percentages of area under positive/negative PCP departures during four typical ENSO events.

\begin{tabular}{c|cc|cc}
\hline \multirow{2}{*}{ Percentages of area } & \multicolumn{2}{|c|}{ El Niño } & \multicolumn{2}{c}{ La Niña } \\
& 1973 & 1998 & 1974 & 2011 \\
\hline Positive departures & $49.2 \%$ & $0.0 \%$ & $53.5 \%$ & $100.0 \%$ \\
Negative departures & $50.8 \%$ & $100.0 \%$ & $46.5 \%$ & $0.0 \%$ \\
\hline
\end{tabular}

\section{Discussion and Conclusions}

In this study, the spatial-temporal variation of $\mathrm{PCD} / \mathrm{PCP}$ and their possible relation with ENSO from 1960 to 2014 in the middle and lower reaches of Yangtze River have been investigated. Major results revealed that:

(1) The annual PCD in this area ranged from 0.3 to 0.5 , while PCP from May to July, which agreed with previous studies (Zhang and Qian, 2003; Wang et al., 2013; Kong et al., 2015). Both PCD and PCP of this region is lower /earlier (for PCP) than most area in China including the upper reaches of Yangtze River (Zhang and Qian, 2003; Wang et al., 2013; Kong et al., 2015). The lower PCD were mainly located in the northeast and south, probably resulting from the long rainy season especially in the seaside and lower latitudes. Meanwhile, the variation of mean PCP across the whole area significantly ranged from May to July, and delayed gradually from south to north, which can be attributed to the fact that the summer monsoon and the subtropical rain belt spread from south to north.

(2) PCD had an increasing trend in the west part while negative in the east. PCP had a trend of advancing mainly in the central part. These results were similar to the study conducted by Wang et al. (2013). The changes in PCD may be related to the number of rainy days (Cortesi et al., 2012), the plum rains season (Wang et al., 2013), summer rainfall (Zhang et al., 2009) or extreme precipitation (Alexander et al., 2006). Besides, there was a significant transition of PCD trend from positive/negative to negative/positive in the southwest/southeast part during two sub-periods. Furthermore, the comparatively high PCD and its positive trend and late PCP in the northwest part indicated that there would be more spring and autumn drought and summer flood (High PCD and Late PCP).

(3) PCD had a weak positive correlation with ONI, while PCP negative. The variation of precipitation pattern is a complicated progress, thus large scale circulation may be a leading factor (Wang et al., 2013). Previous studies had also illustrated that the abnormal precipitation or drought/flood in East Asia (especially China) was usually 
affected by ENSO events (Larkin, 2005; Chen et al., 2013; Shuai et al., 2013; Räsänen et al., 2015). The results of this paper have stated that in El Niño years (high ONI), the rainy season may come earlier and the precipitation may be more concentrated. It could be inferred that El Niño might cause more droughts/floods in the dry/rainy season and earlier rainy season. On the contrary, during La Niña, precipitation would be distributed more evenly and rainy season probably came later.

Though some reliable conclusions have been addressed in this study, there are other issues worthy of more examination in the future study. Firstly, as a time-depend index, PCD is prone to indicate the precipitation symmetry degree during a given period. But this does not coincide with the concept of concentration very well. However, other indices also have some shortcomings. Such as PCI (Oliver, 1980; Luis et al., 2011; Shi et $a l ., 2015)$, which just takes the total rainfall amount into consideration while ignores the timing, and CI (concentration index) based on the contribution of daily precipitation to the total rainfall amount (Martin-Vide, 2004). Hence, the improvement of indicator for reflecting the real concentration of precipitation needs further work.

Secondly, whether the precipitation concentrates or not and whether rainy season comes early or late may also affect corresponding seasonal droughts and floods. It is worth further investigation on the relationships between precipitation concentration and drought/flood indicated by meteorological indices, such as SPI (standardized precipitation index; McKee et al., 1993) and SPEI (standardized precipitation evapotranspiration index; Vicente-Serrano et al., 2010). And the effect of rainfall concentration changes on hydrological cycle and its effect on natural and human processes also need further studies.

\section{Acknowledgements}

The authors would like to thank National Natural Science Foundation of China (Grant no. 41301586) and China Postdoctoral Science Foundation (Grants no. 2014T70731) for providing financial support on this study. We also appreciate the anonymous reviewers' comments on this work.

\section{References}

Alexander, L.V., Zhang, X., Peterson, T.C., Caesar, J., Gleason, B., Klein Tank, A.M.G. 2006. Global observed changes in daily climate extremes of temperature and precipitation. Journal of Geophysical Research Atmospheres 111 (D5), 1042-1063.

Apaydin, H., Erpul, G., Bayramin, I., Gabriels, D. 2006. Evaluation of indices for characterizing the distribution and concentration of precipitation: A case for the region of Southeastern Anatolia Project, Turkey. Journal of Hydrology 328, 726-732.

Arnaud, P., Bouvier, C., Cisneros, L., Domínguez, R. 2002. Influence of rainfall spatial variability on food prediction. Journal of Hydrology 260, 216-230.

Arnoldus, H.M.J. 1977. Methodology used to determine the maximum potential average annual soil loss due to sheet and rill erosion in Morocco. FAO Soils Bulletin 34, 39-51. 
Bai, A., Liu, X. 2010. Characteristics of rainfall variation over east China for the last 50 years and their relationship with droughts and floods. Journal of Tropical Meteorology 16 (3), 255-262.

Chen, W., Lan, X., Wang, L., Ma, Y. 2013. The combined effects of the ENSO and the Arctic Oscillation on the winter climate anomalies in East Asia. Chinese Science Bulletin 58 (12), 1355-1362.

Cortesi, N., Gonzalez-Hidalgo, J.C., Brunetti, M., Martin-Vide, J. 2012. Daily precipitation concentration across Europe 1971-2010. Natural Hazards \& Earth System Sciences Discussions 12 (9), 2799-2810.

De Luis, M., González-Hidalgo, J.C., Brunetti, M., Longares, L.A. 2011. Precipitation concentration changes in Spain 1946-005. Natural Hazards and Earth System Sciences 11 (5), 1259-1265.

Gu, G., Adler, R.F. 2015. Spatial Patterns of Global Precipitation Change and Variability during 1901-2010. Journal of Climate 28 (11), 4431-4453.

Huang, J., Zhang, J., Zhang, Z., Xu, C.Y. 2013. Spatial and temporal variations in rainfall erosivity during 1960-2005 in the Yangtze River basin. Stochastic Environmental Research \& Risk Assessment 27 (2), 337-351.

Huang, P., Xie, S.P., Hu, K., Huang, G., Huang, R. 2013. Patterns of the seasonal response of tropical rainfall to global warming. Nature Geoscience 6 (5), 357-361.

IPCC. Intergovernmental panel on climate change 2013. Fourth Assessment Report (AR4) [M]. Cambridge University Press, Cambridge.

IPCC. Intergovernmental panel on climate change 2013. Fifth Assessment Report (AR5) [M]. Cambridge University Press, Cambridge.

Kong, F., Fang, J., Liu, F., Fang, J., Shi, P. 2015. Variations in the spatiotemporal patterns of precipitation concentration degree and precipitation concentration period from 1951 to 2012 in China (in Chinese with English abstract). Journal of Beijing Normal University (Natural Science) 51 (4), 404-411.

Larkin, N.K. 2005. Global seasonal temperature and precipitation anomalies during El Niño autumn and winter. Geophysical Research Letters 32, L16705. Doi: 10.1029/2005GL022860.

Liu, G., Zhao, P., Chen, J. 2011. A 150-year reconstructed summer Asian-Pacific Oscillation index and its association with precipitation over eastern China. Theoretical and Applied Climatology 103, 239-248.

Martin-Vide, J. 2004. Spatial distribution of daily precipitation concentration index in peninsular Spain. International Journal of Climatology 24 (8), 959-971.

Marvel, K., Bonfils, C. 2013. Identifying external influences on global precipitation. Proceedings of the National Academy of Sciences 110 (48), 19301-19306.

McKee, T.B., Doesken, N.J., Kleist, J. 1993. The relationship of drought frequency and duration to time scales. Eighth Conference on Applied Climatology. American Meteorological Society, Anaheim, CA, pp. 179-184.

Mello, C.R., Viola, M.R., Beskow, S., Norton, L.D. 2013. Multivariate models for annual rainfall erosivity in Brazil. Geoderma 202-203, 88-102.

Munka, C., Cruz, G., Caffera, R.M. 2007. Long term variation in rainfall erosivity in Uruguay: a preliminary Fournier approach. GeoJournal 70, 257-262.

Oliver, J.E. 1980. Monthly precipitation distribution: a comparative index. Professional Geographer 32, 300-309.

Räsänen, T.A., Lindgren, V., Guillaume, J.H.A., Buckley, B.M., Kummu, M. 2015. On the spatial and temporal variability of ENSO precipitation and drought teleconnection in mainland Southeast Asia. Climate of the Past Discussions 11 (6), 5307-5343. 
Renard, K.G., Freimund, J.R. 1994. Using monthly precipitation data to estimate the R-factor in the revised USLE. Journal of Hydrology 157, 287-306.

Shi, P., Wu, M., Qu, S., Jiang, P., Qiao, X., Chen, X., Zhang, Z. 2015. Spatial Distribution and Temporal Trends in Precipitation Concentration Indices for the Southwest China. Water Resources Management 29 (11), 3941-3955.

Shuai, J., Zhang, Z., Sun, D.Z., Tao, F., Shi, P. 2013. ENSO, climate variability and crop yields in China. Climate Research 58 (2), 133-148.

Silva, B.K.N., Lucio, P.S. 2015. Characterization of risk/exposure to climate extremes for the brazilian northeast-case study: Rio Grande do Norte. Theoretical \& Applied Climatology, $122(1-2), 1-9$.

Stott, P.A., Gillett, N.P., Hegerl, G.C., Karoly, D.J., Stone, D.A., Zhang, X., Zwiers, F. 2010. Detection and attribution of climate change: a regional perspective. Wiley Interdisciplinary Reviews: Climate Change 1 (2), 192-211.

Vicente-Serrano, S.M., Beguería, S., López-Moreno, J.I. 2010. A Multiscalar Drought Index Sensitive to Global Warming: The Standardized Precipitation Evapotranspiration Index. Journal of Climate 23 (7), 1696-1718.

Wang, B., Ho, L. 2002. Rainy Season of the Asian-Pacific Summer Monsoon. Journal of Climate $15,386-398$.

Wang, Q., Wu, J., Lei, T., He, B., Wu, Z., Liu, M., Liu, D. 2014. Temporal-spatial characteristics of severe drought events and their impact on agriculture on a global scale. Quaternary International 349, 10-21.

Wang, W., Xing, W., Yang, T., Shao, Q., Peng, S., Yu, Z. 2013. Characterizing the changing behaviours of precipitation concentration in the yangtze river basin, china. Hydrological Processes 27 (24), 3375-3393.

Zhai, J., Su, B., Krysanova, V., Vetter, T., Gao, C., Jiang, T. 2010. Spatial Variation and Trends in PDSI and SPI Indices and Their Relation to Streamflow in 10 Large Regions of China. Journal of Climate 23 (3), 649-663.

Zhang, L., Qian, Y. 2003. Annual distribution features of the yearly precipitation in China and their interannual variations. Acta Meteorological Sinica 17 (02), 146-163.

Zhang, L., Qian, Y. 2004. A study on the feature of precipitation concentration and its relation to flood-producing in the Yangtze River valley of China (in Chinese with English abstract). Chinese Journal of Geophysics 47 (4), 622-630.

Zhang, Q., Xu, C.Y., Zhang, Z., Chen, Y.D., Liu, C.I., Lin, H. 2008. Spatial and temporal variability of precipitation maxima during 1960-2005 in the Yangtze River basin and possible association with large-scale circulation. Journal of Hydrology 353 (3-4), 215-227.

Zhang, Z., Zhang, Q., Xu, C., Liu, C., Jiang, T. 2009. Atmospheric moisture budget and floods in the Yangtze River basin, China. Theoretical \& Applied Climatology 95 (3-4), 331-340. 